\title{
Furniture arrangement for children with autism
}

\author{
BAVITA AND SHALINI AGARWAL
}

Received: 06.05.2017; Revised: 13.11.2017; Accepted: 27.11.2017

See end of the paper for authors' affiliations

\section{BAVITA}

School of Home Science, Babasaheb Bhimrao Ambedkar University (Central University), Vidya Vihar, Raebareli Road, LUCKNOW (U.P.) INDIA

Email : bavita51289@gmail.com
ABSTRACT : Autism is a complex neurobehavioral disorder characterized by impairment in social interaction, impairment in communication, and the presence of repetitive and stereotypic patterns of behaviour's, interests and activities. Autism affects the functions of the brain, it can be seen when children are three years old. The logo of Autism is puzzle, because Puzzle indicates the mystery and complexity of Autism. There are several occasions about the creation of architectural environments suitable for people with ASD. Ample spaces, to allow the development of the children's activities without excessive proximity, avoiding too polished materials, for instance some times it is difficult to combine this aspect with the need to clean the flooring-soft materials like carpet can be useful to absorb noise, but the downside is that they are harder to clean than shinier ones, whose acoustic behaviour can be problematic. Safety is important when designing showers and toilets, and therefore pipes must not remain exposed, and fittings must be firmly fixed -otherwise they could be pulled out of their place. It is also necessary to provide enough common showers and toilets because incontinence is not a rare problem in some children with autism, Colour palette should be adequately chosen, in order to create environments that provide a warm but not over stimulating atmosphere, floor heating or radiant ceiling panels, and cross-ventilation, preferably from bottom to top, by means of two windows placed in opposite walls. Avoid traditional fluorescent lamps, as people with ASD might be greatly sensitive to the flickering produced by them, even though other people will never notice it.

KEY WORDS: Autism, Social, Communication, Behaviour, Space, colour, Ventilation

- HOW TO CITE THIS PAPER : Bavita and Agarwal, Shalini (2017). Furniture arrangement for children with autism. Asian J. Home Sci., 12 (2) : 636-641, DOI: 10.15740/HAS/AJHS/12.2/636-641. 